\title{
Study on Effect of Productivity on Applying Ergonomic Principle
}

\author{
Kanitha Mani ${ }^{\# 1}$, Sasi Kumar Mani ${ }^{\# 2}$ \\ \# Faculty of Civil Engineering, M.Kumarasamy College of Engineering, Karur \\ ${ }^{1}$ kanithamani@gmail.com ${ }^{2}$ sasi.mj@gmail.com
}

\begin{abstract}
This study was to investigate the effect of productivity in the construction industry due to the unergonomic working atmosphere. The construction industry is a large number of workers concerning industry it leads to productivity loss or due risk factors in the working site. In the review, to improve analysis a drawback, we took ergonomic awareness questionnaire survey among the Engineers in Karur district. Based on the survey results, the awareness of term ergonomics is only $\mathbf{2 0} \%$ and Engineers accept to adopt the ergonomics principles. We extended our work to apply ergonomic principles in the site. The ergonomic deficiency was identified, and gradually new ergonomic principles were applied in plastering and brickwork. $1 \%$ increase in productivity measured at 7 days of implementation.
\end{abstract}

Keyword-Construction site, Ergonomics principles, Ergonomic Risk Factors.

\section{INTRODUCTION}

Ergonomics is the study of the interaction between people and machines and the factors that affect the interaction. Its purpose is to improve the performance of systems by improving human-machine interaction. The focus is on the interaction the person and the machine and the design of the interface between the two. Every time we use a tool or a machine, we interact with it via an interface. The construction industry workers are working with uncomfortable due to lack of awareness about the working posture. The International Labour Organization (ILO) indicates that Musculoskeletal Disorders are the reason for 40 illness and reduce productivity in most of the countries all over the world[6]. Mostly old age workers are having a high quality of work.[7] But the implementation of ergonomic principle on them is difficult. By working with the uncomfortable circumstances, the worker's ability to work can be reduced. Productivity also gets affected by ergonomics risk factors. Productivity can be increased by improving the worker's efficiency by implementing ergonomics principles. Ergonomics principles are fundamental concepts that explain how to work in a situation properly and safely. This principle taught that workers could work with full efficiency without body pain or other disorders. Back injuries are the most common type of injuries accrued for workers according to American and European studies.[4] the ergonomic analysis requires time and data collection.[1] "Participatory ergonomics means actively involving workers in developing and implementing workplace changes which will improve productivity and reduce risks to safety and health" - or as Wilson (1995)[4]. By the ergonomics principles, the workers can work comfortably. It is necessary to implement the ergonomics principles on workers to get their maximum efficiency with the workers comfortably. When the worker works with maximum efficiency and in better comfort the worker can do more quantity of work. The productivity can be increased by the implementation of ergonomics principles on workers on the construction site. Currently, the most significant motivator for ergonomics are organizations such as OSHA and NIOSH or other equivalents in other countries.[3] MSDs can also lead to significant financial losses. [5] The objective of an ergonomic programme is to provide a safe, productive workplace and fulfil objectives of the organisation.

\section{WORK-RELATED MUSCUlOSKELETAL DisORDERS}

The Repetitive task is of interest to ergonomics because of their potential to cause musculoskeletal pain, to cause injuries, or to exacerbate pain from the existing musculoskeletal condition. The effectiveness of any ergonomic improvements at the workplace may be palliative but will not prevent or cure these conditions.

International Classification of Diseases (ICD) Diagnoses for Work-Related Musculoskeletal Disorders (WMSDs)

1. Nerve Root and Plexus Disorder

i) Brachial plexus lesions

ii) Unspecified nerve and plexus disorder

2. Mononeuritis of the Upper Limb and Mononeuritis Multiplex

i) Carpal tunnel syndrome

ii) lesions of the ulnar nerve

iii) Lesions of the radial nerve 
The main occupational factors associated with musculoskeletal conditions at work are,

1. Force

2. Posture

3. Repetition

4. Duration

5. Stress/anxiety

\section{ERGONOMICS AWARENESS SURVEY}

An awareness survey was conducted among the civil engineers in Karur region. The aim of the survey to collect information about the awareness of ergonomics and create awareness to civil engineers about ergonomics principles. Collection of data about the comfort and risk level in the construction site in our region. The Implementation survey also included by following.

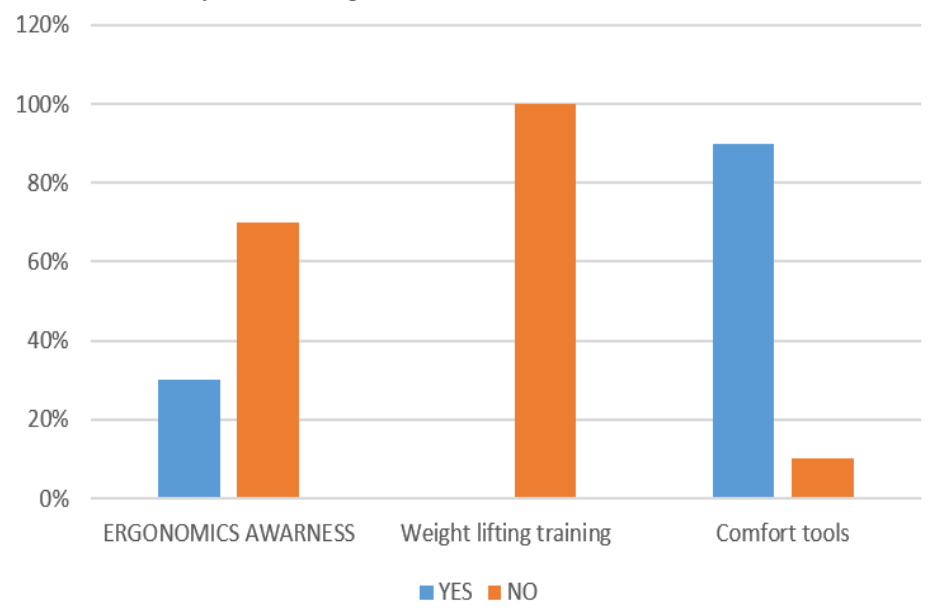

Fig. 1. Questionaries results chart

\section{A. Awareness Survey on Engineers}

The ergonomics awareness among the civil engineers is only $30 \%$ and the remaining $70 \%$ of the civil engineers are not aware of the concept ergonomics. Most of the civil engineers are not aware of the ergonomic risk factors on the construction site. The construction industry is one of the most risk factors present among all industries. To reduce the risk and hazard present in site the engineers must be aware about the ergonomics. The engineers should care about the worker's work-related disorders. The problem is nearly $70 \%$ of the engineers are not aware of the ergonomics, so the worker's work-related problems are not identified and not solved.

\section{B. Survey on Weightlifting}

In weightlifting the workers are uncomfortable, nearly $98 \%$ of the organizations did not provide any kind of weightlifting training programs to the workers in the Karur region. Weightlifting programs are important to the uneducated workers. By not aware of the weightlifting the worker's do their work in uncomfortable. Worker's getting Work-Related Musculoskeletal Disorders due to carry the overweight continuously. By providing the weightlifting programs with the worker's get awareness about the risk present in carrying overweight. WorkRelated Musculoskeletal Disorders can be reduced.

\section{Survey on Power Equipment's}

Power equipment tools provide vibration and body pain to the workers while working, nearly $90 \%$ of the organization brought power tools by considering the comfort of the workers. $10 \%$ of the organization did not consider comfort. Most of the organizations are not considering the worker's comfort in using power equipment's. Power equipment provides more vibrations to workers. Continuous vibrations provide nerves disorder to the workers. By using comfort power equipment's, the worker can finish the work in less duration with more comfort.

\section{Survey on Weight Restriction}

In weight restriction $25 \%$ of the organization provides weight restriction on workers in a construction site, remaining $75 \%$ of the organization does not provide any weight restrictions. The workers do not have enough knowledge about the weight carrying. The engineers must provide weight restriction on workers, so the workers can carry restricted weight on the construction site. Worker's getting Work-Related Musculoskeletal Disorders due to carry the overweight continuously. The weight restriction on workers varies based on the worker's age category. By carrying only, the restricted weight the workers can work more comfortable. So, productivity can be gradually increased. 


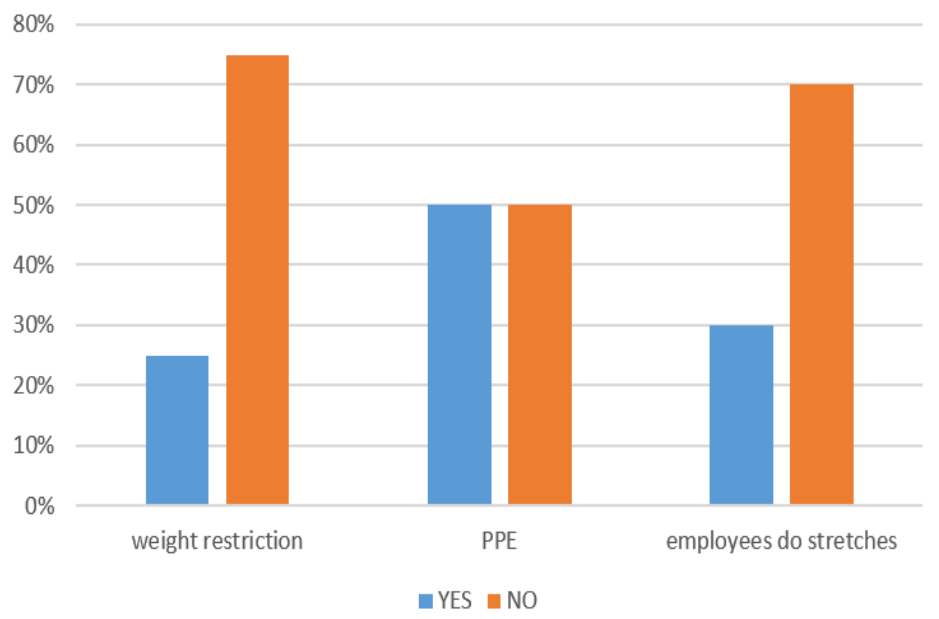

Fig. 2. Survey results on safety measures in site

\section{E. Survey on Personal Productive Equipment's}

$50 \%$ of the organization provides Personal Productive Equipment to workers in a construction site. Personal productive equipment's are used to reduce the risk level present in the construction site. Mostly the workers are not aware of the PPE. Engineers should provide the PPE to the workers and make aware of them. By using PPE the workers can work more comfortable, so the work duration can be reduced. Using the exact PPE for specific work the quality of the work can increase in less duration. Once the workers used to learn work by using Personal Productive Equipment's they can adopt to work safely and comfortably. So, the productivity can be increased by using Personal Productive Equipment's.

\section{F. Survey on Stretches}

Only $30 \%$ of the site workers do stretches while heavy work, the remaining $70 \%$ of the worker's do heavy work without any stretches. Working continuously more time the workers feel uncomfortable. Work-Related Musculoskeletal Disorders affects the worker's when they work uncomfortable. By working uncomforted the quality of the work reduces and the duration of the work increases. The workers can take stretches in-between the work, so the body pain can be reducing, and the comfort level could be increased. So, the productivity can be increased by using the stretches by the workers.

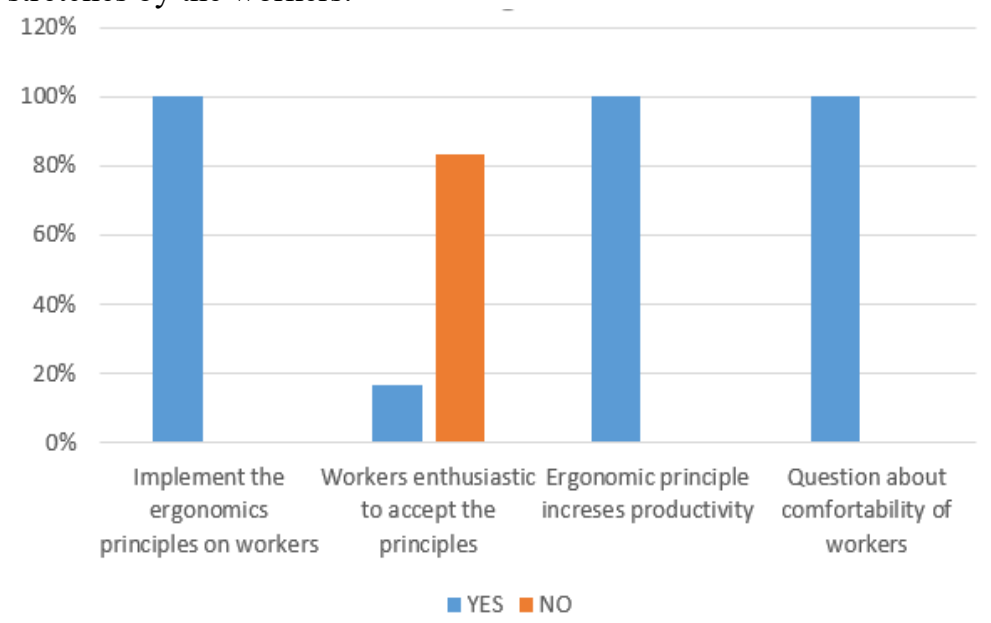

Fig. 3. Survey results on Stretches for labours

\section{G. Survey on Implementation of Ergonomic Principles}

According to the survey, nearly $98 \%$ of the engineers are ready to implement the ergonomics principles on workers, but only $16.60 \%$ of the workers enthusiastic to accept the changes on their working methods, remaining $83.40 \%$ of the workers not ready to accept the changes on their working method. The engineers are ready to make an implement the ergonomic principle on workers but the workers are not enthusiastic to accept the implementation on them. Because the workers are not aware of the disorders. To increase productivity, engineers must create awareness about the ergonomic principles and make them accept the implementation. 
Most of the organizations accept the idea that the ergonomics principles implementation on workers will increase the overall productivity. But they are not implementing the ergonomic principles because the workers are not enthusiastic to accept the ergonomic principles. The questions about the comfortability of workers are asked by the organization. By asking a question about the comfort ability of workers the engineers can know about comfort and risk level of the construction site.

\section{H. Survey on Work Comfort and Risk Level in Construction Sites}

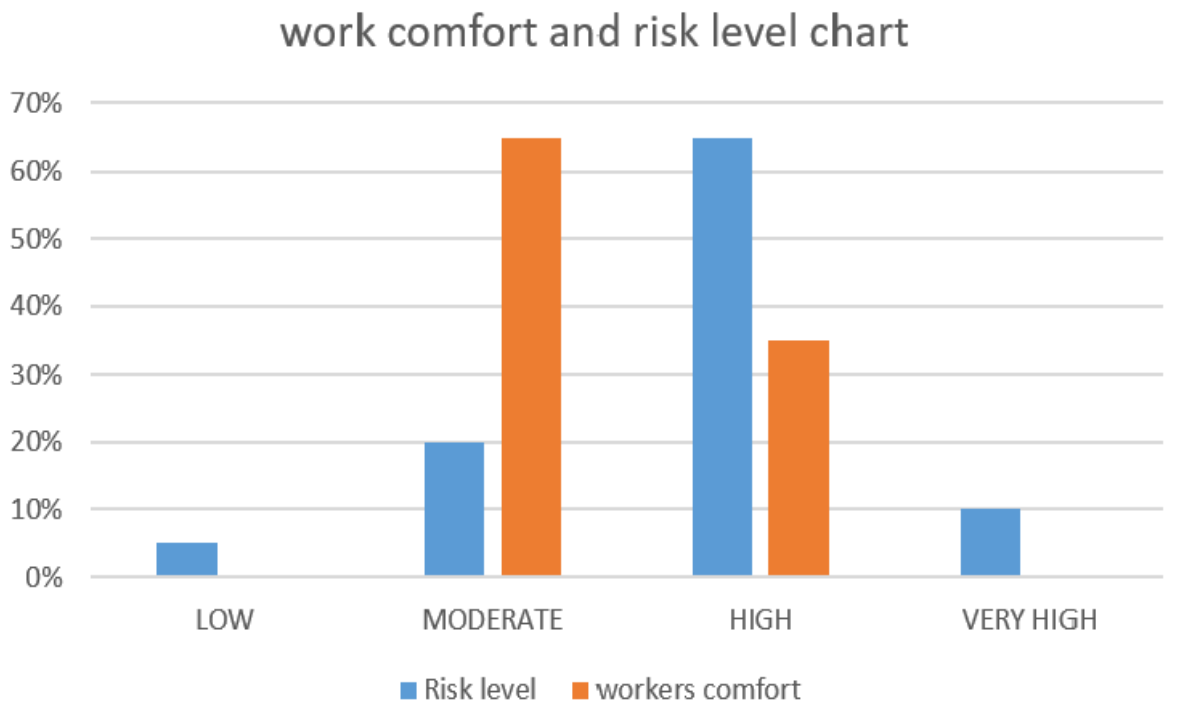

Fig. 4. Work Comfort and Risk Level

According to the survey conducted for worker's comfort and risk level, the risk level present at low is $5 \%$, $20 \%$ of workers works at a moderate risk level. Most of the worker's works at the high-risk level, the percentage of workers at a high-risk level is $65 \%$. The remaining $10 \%$ of the worker's works at a very high-risk level. $65 \%$ of the construction site contains high-risk level because $50 \%$ of the construction sites providing the Personal Productive Equipment's to the workers. If the risk level reduces the comfort level could be increase and the productivity can be increased.

In the worker's comfort, Most of the worker's works at a moderate comfort level. Nearly $65 \%$ of worker's works at a moderate comfort level. Only $35 \%$ of worker's works at a high comfort level in the construction industry. No workers work at a high comfort level. The comfort level of the workers reduces because of the ergonomic risk factors. The graph clearly shows that the risk level is low when the comfort level is high. By implementing the ergonomics risk factors, the comfort level of the workers will be increased.

\section{IMPLEMENTATION AT Site}

A construction site was adopted in Karur city and the existing condition of the site was studied. The identified Ergonomic Risk Factors are,

1. Awkward posture

2. Repetition

3. Vibration

4. Inadequate light

5. Static posture

Table 1: Ergonomic Risk Factors

\begin{tabular}{|l|c|c|c|}
\hline \multicolumn{1}{|c|}{ Description } & Plastering Work & Brick Work & Hacking Work \\
\hline Repetition & $\checkmark$ & & \\
\hline Awkward Posture & $\checkmark$ & $\checkmark$ & $\checkmark$ \\
\hline Static Posture & $\checkmark$ & $\checkmark$ & $\checkmark$ \\
\hline Vibration & & & $\checkmark$ \\
\hline Inadequate Lighting & $\checkmark$ & & \\
\hline
\end{tabular}




\section{A. Awkward Posture}

For the body to be stable, the combined of gravity $(\mathrm{COG})$ of the various body parts must fall within a base of support. The various work that affected by awkward postures are,

1. Brickwork

2. Plastering work

3. Hacking work

4. Works using heavy equipment's.

The awkward posture increases the Work-Related Musculoskeletal Disorders to the workers.

\section{B. Repetition}

The worker works a similar kind of work in continuous for every few seconds without a break time is repetition. In the construction site, the repetition risk factor is present in

1. Concrete pouring

2. While operating a concrete mixer machine

3. Crane operation

4. Using driller machines for a long time

5. Shifting the materials

By repetition work, the workers feel uncomfortable and increase body pain.

\section{Vibration}

The vibration risk factor occurs when the worker works with highly vibrated tools for a long time. The vibrating tools used in the site was,
1. Vibrators
2. Drillers
3. Concrete breakers
4. Compactors
5. Hammer drills
6. Chainsaws
7. Crane

While purchasing the power equipment tools comfortability to workers should be checked. Fewer vibration tools must be used for construction work.

\section{Inadequate Light}

The worker's comfort was affected by poor lighting on the site. It also affects the worker's eyesight. The quality of the work also gets affected by poor lighting and it takes more duration to finish the work. If the quality reduced and the duration increases than the productivity decreases.

\section{E. Static Posture}

The worker works for continuously without changing the posture for a long duration. This condition is a combination of posture, duration, and force. The static posture reduces the worker's comfortability.

\section{PRODUCTIVITY ANALYSIS}

\section{A. Plastering Work}

The existing work condition for plastering workers was studied. Their work method was analysed and the ergonomics risk factors were identified. The plastering work was done for some days is 1434.87 sq.ft. The crew work done for a single day is 286.974 sq.ft. A single person works the average of 143.487 sq.ft/day. The organization recommended productivity for a single person for one day is 150 sq.ft. The productivity variance is 6.513 sq.ft/day. The percentage of productivity reduced is $4.34 \%$ per day for one plastering worker. The ergonomic risk factors identified on plastering work was awkward posture, inadequate light.

The Ergonomic Principles were implemented on the plastering workers were Maintain Neutral Posture, providing adequate light. The total plastering work done after the implementation of ergonomic principles is 1453.731 sq.ft. The total work done for a crew in one day is 290.746 sq.ft. A single person average work done for one day is $145.373 \mathrm{sq} . \mathrm{ft} /$ day. The productivity variance is $4.627 \mathrm{sq} . \mathrm{ft} /$ day for one person. The percentage of reduced productivity for one person in one day is $3.08 \%$. The average productivity of one person increases to 2 sq.ft/day.

\section{B. Brickwork}

The brickwork was studied on the existing work condition. The total brickwork done in some days is 155.72 cu.ft. Total brickwork done by a crew in one day is 31.144 cu.ft/day. For one person the total brickwork done in 
one day is $15.572 \mathrm{cu} . \mathrm{ft} / \mathrm{day}$. The ergonomic risk factors were identified on brickwork is awkward posture, repetition.

After implementing the ergonomics principles on workers, the increased productivity was calculated. The total work done in some days after the implementation of principles is $157.39 \mathrm{cu} . \mathrm{ft}$. The average productivity for a single day is 31.478 cu.ft. Average productivity for one person for one day is $15.739 \mathrm{cu} . \mathrm{ft} / \mathrm{day}$. The average productivity increased by $0.17 \mathrm{cu}$.ft/day for a single person. $1.1 \%$ of daily productivity increased for each worker.

\section{Hacking Work}

The hacking work was done by using cutters with vibrations. This work was done before the plastering work. Hacking work was calculated by hours. Before the implementation of ergonomic principles, the work done by the hacking worker is 805.45 sq.ft. This work was done in a period of 3 hours. The average work done for 1 hour is 268.5 sq.ft. The ergonomic risk factors identified in hacking work was vibration and awkward posture.

After corrections, the productivity was 1078.63 sq.ft for 4 hours. The average productivity for 1 hour is 269.65 sq.ft. The worker's average 1 -hour productivity is increased by 1.15 sq.ft/hour. $0.42 \%$ of the worker's productivity is increased by 1 hour.

Table 2: Difference in Productivity of the Various Work

\begin{tabular}{|l|c|c|c|}
\hline \multicolumn{1}{|c|}{ Category } & Plastering Work & Brick Work & Hacking Work \\
\hline Principles before implemented & 143.487 sq.ft & 15.572 cu.ft & 268.5 sq.ft \\
\hline Principles after implemented & 145.371 sq.ft & 15.739 cu.ft & 269.65 sq.ft \\
\hline Productivity increased & $1.3 \%$ & $1.1 \%$ & $0.42 \%$ \\
\hline
\end{tabular}

\section{CONCLUSION}

In this project, the ergonomic awareness survey was conducted on civil engineers in the Karur region. Nearly $70 \%$ of the engineers are not aware of the ergonomics. Mostly $65 \%$ of workers work at a moderate level and the risk level present in the site is high at $65 \%$. Productivity increase at plastering work is $1.3 \%$. In brickwork, $1.07 \%$ productivity increased. The implementation of the ergonomic principles on workers is going to be a necessary factor in future. Because the demand for quality workers and experienced workers may increase in future. At present, the organization should care about the workers' health condition. The implementation of ergonomic principles is a long term process the productivity increases only gradually after an initial decrease. Once the workers adopted and work nature is changed then the productivity will increase.

\section{REFERENCE}

[1] Alireza Golabchi, Xingzhou Guo, Meiyin Liu, SangUk Han, SangHyun Lee, Simaan AbouRizk An integrated ergonomics framework for evaluation and design of construction operations

[2] Enrique Valero, Aparajithan Sivanathan, Frédéric Bosché, Mohamed Abdel-Wahab. Analysis of construction trade worker body motions using a wearable and wireless motion sensor network.

[3] Gopireddy. M, M. Reddy, B. Nisha, Thangaraj.G,Prabhushankar, and V. Vishwambhar. Musculoskeletal morbidity among construction workers: A cross-sectional community-based study.

[4] https://ergo-plus.com/

[5] International Labour Organization (ILO) (2002). Recommendation concerning the list of occupational diseases and the recording and notification of occupational accidents and diseases (Recommendation R194). Geneva, Switzerland: ILO

[6] Joachim Vedder, Eilı' s Carey. A multi-level systems approach for the development of tools, equipment and work processes for the construction industry

[7] K. S. LEE, Ergonomics in total quality management: How can we sell ergonomics to management?

[8] M. Gervais, Good management practice as a means of preventing back disorders in the construction sector

[9] Mojtaba Valinejad Shoubi, Azin Shakiba Barough, Amin Rasoulijavaheri. Ergonomics Principles and Utilizing It As a Remedy for Probable Work Related Injuries in Construction Projects

[10] Nipun D. Nath, Reza Akhavian, Amir H. Behzadan. Ergonomic analysis of construction worker's body postures using wearable mobile sensors

[11] Ndukeabasi Inyang; Mohamed Al-Hussein, P.Eng., M. ASCE; Marwan El-Rich; and Saad Al-Jibouri, Ergonomic Analysis and the Need for Its Integration for Planning and Assessing Construction Tasks

[12] Occupational Safety and Health Administration 
[13] Peregrin Spielholz; Gary Davis; and Jason Griffith, Physical Risk Factors and Controls for Musculoskeletal Disorders in Construction Trades

[14] S. Eaves, D.E. Gyi, A.G.F. Gibb. Building healthy construction workers: Their views on health, wellbeing and better workplace design

[15] Satish B Mohan, Identifying and Controlling Ergonomic Risk Factors in Construction.

[16] Soumitry J. Ray, Jochen Teizer, Real-time construction worker posture analysis for ergonomics training

[17] Wilson, J.R., 1995. Ergonomics and participation. In: Wilson, J.R., Corlett, E.N. (Eds.), Evaluation of Human Work, second ed. Taylor and Francis, London.

[18] Woojin Park, Devender P. Singh,Martin S. Levy \&Eui S. Jung, Obesity effect on perceived postural stress during static posture maintenance tasks.

\section{Author PRofiLe}

Kanitha Mani Construction Management expert from Builders Engineering College. Completed Bachelor of Engineering in Civil Engineering from Avinashilingam University for Women and Master of Engineering in Construction Engineering and Management from Builders Engineering College. She is currently a full-time faculty as Assistant Professor at the Department of Civil Engineering, M.Kumarasamy College of Engineering, Karur.

Sasi Kumar Mani Construction Management expert from Kongu Engineering College. Completed Bachelor of Engineering in Civil Engineering from K.S.Rangasamy College of Technology and Master of Engineering in Construction Engineering and Management from Kongu Engineering College. He is currently a full-time faculty as Assistant Professor at the Department of Civil Engineering, M.Kumarasamy College of Engineering, Karur. 